\title{
Teaching teamwork to transnational students in engineering and technology
}

\author{
Rami Ghannam ${ }^{1}$ and Wasim Ahmad \\ Engineering Education Research Group, University of Glasgow, UK.
}

\begin{abstract}
Western countries are simply not producing enough graduate engineers. Higher education institutions therefore need to consider re-designing their engineering programmes. In the meantime, China is producing over eight million science, technology, engineering and mathematics (STEM) graduates each year. According to the literature, many of these graduates lack the professional skills that are required by the global job market. Consequently, a course was designed in 2016 between the University of Glasgow (UoG) and the University of Electronic Science and Technology of China (UESTC) to help transnational students in China to cultivate the professional knowledge and practical skills needed in the field of electronic engineering. The aim of this innovative course was to build experience of working in a team to design and develop, within a budget, a rover that performs specific tasks. The course's project covers areas such as electronic design, sensing, instrumentation, measurement, computing and communications, as well as project management, report writing and technical presentation. The learning outcomes and course details are described in this paper. This article describes the learning experiences of 152 Chinese students who took part in our online survey, which aimed to find out student preferences towards teamwork and team-based learning. To appreciate the cultural differences, our results were compared with feedback from a similar survey implemented for a team-based activity in the United Kingdom (UK). Our survey's results clearly show that this team-based activity was ideally suited to the culture and background of our transnational students in China. Statistical analysis from the two surveys also showed that students valued the teamwork experience, which helped them learn more in comparison to individual study. We therefore believe that these team-based activities can help attract more students to engineering degrees and retain them.
\end{abstract}

Keywords: Active Learning, Teamwork, Engineering Education, Course Design.

\section{Introduction}

Since the invention of the transistor in the late 1940s, the field of electronic engineering has witnessed a rapid transformation. Faced with this fast-growing discipline, students are expected to develop strong technical expertise as well as the team-working and communication skills required by the global job market. Achieving these needs is a major challenge in the light of declining numbers of science, technology, engineering and mathematics (STEM) applicants in many Western nations. Effective teaching methods are

\footnotetext{
${ }^{1}$ Corresponding author: Rami Ghannam, James Watt School of Engineering, University of Glasgow, University Avenue, Glasgow G12 8BP, United Kingdom.

Email: rami.ghannam@glasgow.ac.uk
} 
therefore required to address these issues and to cope with the key economic challenges related to STEM graduates in many Western countries (Great Britain, Department for Business Energy and Industrial Strategy, 2017; Olson and Riordan, 2012).

Despite the rapidly evolving field of engineering, the discipline is still taught using traditional teacher-centred methods. The literature clearly indicates a lack of student engagement during engineering classes. In fact, research has shown that up to sixty per cent of engineering classes lack any form of active learning (Finelli et al., 2014). Since universities typically reward research productivity rather than teaching excellence, faculty members are often reluctant to adopt new teaching approaches that replace teacher-centred methods (Carberry and Baker, 2018). Furthermore, some faculty falsely believe that implementing active learning is more appropriate for majors in the arts and social sciences than for engineering (Carberry and Baker, 2018). Consequently, these factors are among the barriers to successfully attracting new STEM applicants (Ejiwale, 2013), especially in service economies such as the United Kingdom (UK). Meanwhile, China's manufacturing-based economy produces almost double the number of STEM graduates than does the Western world (Stapleton, 2017, Han and Appelbaum, 2018). Rapid economic growth, driven by manufacturing, is a key factor behind this difference in the number of STEM graduates. Nevertheless, many of these graduates lack the teamwork, communication and presentation skills needed by the global job market (British Council, 2018, Chan et al., 2015). Therefore, as module leaders and staff members in the Glasgow College-UESTC programme, we aimed to ensure that our transnational students acquired these skills via a third-year module called Team Design Project and Skills (TDPS).

Without doubt, teaching that relies on instructors who dictate at the blackboard makes it more difficult for students to become independent learners (Miller and Euchner, 2014). These traditional lecture formats typically result in poor exam performance by students (Vogt, 2008), who are at least one and a half times more likely to fail a course than those attending classes that implement active learning methods (Freeman et al., 2014). It is therefore now crucial to overcome some of these cultural influences by designing and delivering courses promoting active learning methods to prepare graduates for twenty-first century global challenges (Ahmad et al., 2019). Such learning methods have demonstrated improved student performance in STEM subjects by up to six per cent (Freeman et al., 2014; Hake, 1998).

Team-based learning (TBL) is an active, collaborative teaching and learning technique initially developed for business education (Haidet and Fecile, 2006). It is a teaching strategy proven to promote effective teamwork skills (Gallegos and Peeters, 2011). According to Zgheib et al. (2010), Vasan et al. (2011) and Thomas and Bowen (2011), TBL has been clearly shown to improve student performance in exam results. Many studies actually report successful practices in the teaching of teamwork in the classroom. Moreover, strong teamwork skills are now considered essential for engineering graduates and professionals. Owing to the growing skills gap articulated by industry, accreditation bodies now require higher education institutions (HEls) to include teamwork skills in their engineering programmes (Dunne and Rawlins, 2000). According to the UK's Institution of Engineering and Technology (IET) accreditation requirements, students must demonstrate "an awareness of team roles and the ability to work as a member of an engineering team" (Engineering Council, 2014). The most common practice for achieving this requirement was 
simply to assign group projects within the laboratory component of technical courses (Price et al., 2010). However, this practice is inadequate for actively developing team-working skills in students who are in the process of becoming independent learners (Gallegos and Peeters, 2011). In fact, courses should be designed so that students transform their teams into effective learning environments (Murzi, 2014; Freeman, 2012).

TBL involves more than just splitting students into groups - it combines pre-class guided self-learning with interactive group learning, which takes place during class. There are three main components of TBL, as shown in figure 1 (Michaelsen and Sweet, 2008). The first is the 'Preparatory Phase', during which instructors provide guided learning materials for the students to master course fundamentals and objectives. Next is the 'Readiness Assurance Phase', which involves probing and assessing individual student understanding of the guided or surface learning materials. The same assessment exercise is then delivered to the teams, the members of which must discuss the questions and agree on the answers among themselves. Once this is achieved, the instructor must provide feedback to the teams and discuss the key learning concepts. Finally, Phase 3, 'Team Application', involves assigning a team project that involves collaboration, critical thinking and the concepts learned in Phases 1 and 2.

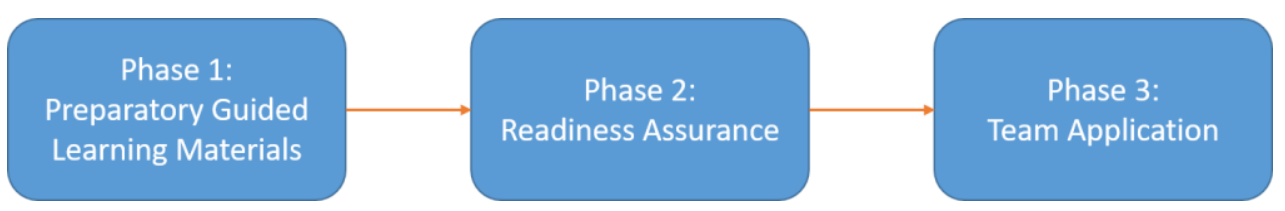

Figure 1: Main components of TBL (Michaelsen and Sweet, 2008).

In this paper, we demonstrate how a new third-year course was designed to encourage and teach teamwork skills in China; it was called Team Design Project and Skills (TDPS) (Ghannam, 2019). Like Zhang et al. (2014) we believe that this practice will help attract more students to engineering degrees. We also believe that TBL is particularly beneficial for teaching large cohorts, since it enables multiple teams to be facilitated by a single instructor, rather than by multiple instructors (Parmelee et al., 2012).

\section{Course design methodology}

According to Michaelsen, TBL works best when it is tightly integrated within a course's design (Parmelee and Michaelsen, 2010). Thus, during the initial stages of planning this new course, our approach to course design and delivery was split into four stages, as shown in figure 2. These were the preparation, methodology, assessment and evaluation stages. Our practice aligned well with the methods described in (Fry et al., 2008) and involved going through a checklist of essential items that included:

1. defining the learning outcomes of the course;

2. determining the level of the course and the intended audience;

3. determining the teaching and learning methods that will be adopted throughout the course;

4. identifying the resources that will be available;

5. understanding the course duration;

6. determining the assessment and evaluation methods. 


\subsection{Preparation}

The preparation phase was concerned with defining the course's intended learning outcomes (ILOs), determining the course's level and intended audience, preparing the subject content and drafting the assessment mechanisms. By the end of the course, students should have developed the following learning attributes and can:

- analyse technical requirements to develop an overall design plan;

- design, assemble and test electronic hardware to perform specific functions;

- design, populate and test printed circuit boards;

- interface electronic and electrical (power) systems;

- select and use appropriate components using the manufacturers' information, including data sheets;

- maintain control of a project budget;

- maintain a personal technical laboratory notebook;

- use a project planning methodology to keep track of progress;

- run a project without undue reliance on a supervisor;

- perform productively as a team, recognising contributions from all team members;

- analyse published information critically for its content, arguments and validity;

- write a concise researched technical report that clearly addresses and analyses pertinent issues;

- use appropriate language and style, demonstrating effective command of English including some complex usage;

- read and understand the essential elements of a scientific or engineering article.

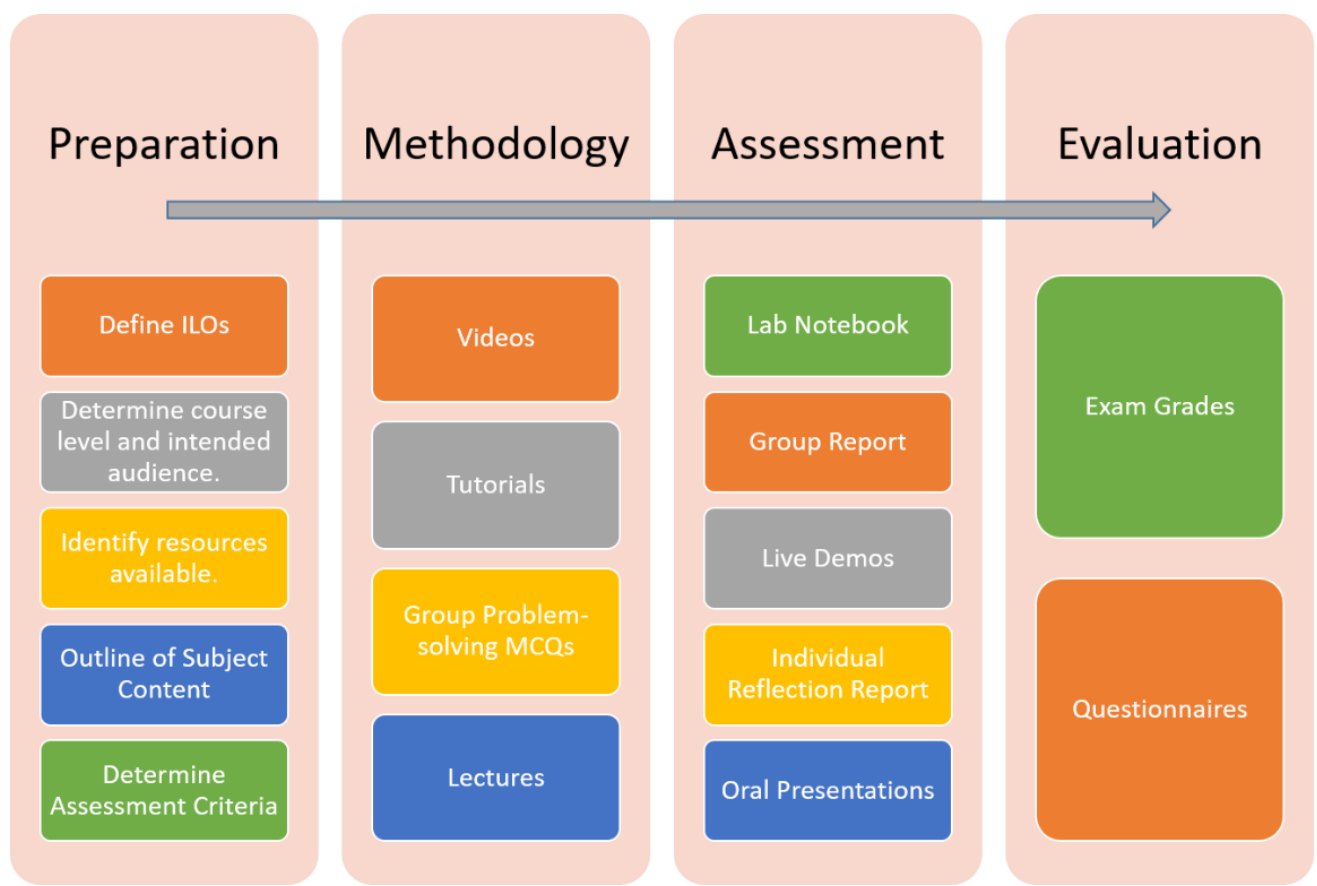

Figure 2: The course matrix used for designing and delivering the TDPS course, showing the elements to be developed at each stage

\subsection{Methodology}

The methodology phase was concerned with planning the course's delivery methods according to the requirements of the preparation phase. As mentioned by Zhang et al. (2014), students cannot simply acquire team-working skills via impromptu project 
experience. Rather, these are skills that should be taught, practised and assessed, just like other academic skills. Research by the American Society for Engineering Education (ASEE) (Jamieson and Lohmann, 2012) confirms that innovative teaching practices are necessary in order for students to acquire these skills. We therefore developed a specific module that aimed to achieve this. To start, we prepared lecture slides on best practices in maintaining a laboratory notebook, as well as guidance on managing a project using deliverables, milestones and Gantt charts. Students were also introduced to the essentials of task distribution and team leadership.

The team-based activity involved splitting students into groups of eight. According to the literature, there are three main approaches for the formation of student teams: self-selection, random assignment and teacher assignment (Bacon et al., 1999). For our course, we chose the teacher assignment method to ensure a fair representation of gender and academic ability in each team. All teams worked on the same problem and reported their decisions simultaneously. This format therefore required teams to articulate their thinking and gave them an opportunity to evaluate their own reasoning.

\subsection{Assessment}

The assessment phase involved finalising the assessment mechanisms, using the information from the preparation and methodology phases. The team project involved designing and developing, within a given budget, a smart rover that would execute certain tasks along required routes. A similar exercise had previously been used to promote teamwork in a third-year undergraduate electronic engineering programme in Australia (Price et al., 2010). We therefore aimed to investigate the impact of a similar exercise on Chinese engineering students. Moreover, there was no mention of any preparatory or readiness assurance phases of TBL in Price's article. Consequently, given the benefits of multiple choice questions (MCQs) described in O'Dwyer (2007), Baig et al. (2014), Williams (2006) and Moeen-Uz-Zafar Khan (2011), we prepared ten MCQs to test student understanding of the key concepts and ILOs of the course ${ }^{2}$. These questions were attempted first by individuals and then by teams. In our case, MCQs were used to ensure that students had grasped the necessary guided-learning materials.

Finally, the culmination of the group work was to be a contest, in which student robots competed against each other to complete a number of tasks along two routes. In general, students had to design rovers that would accomplish various tasks, including colour detection, line tracing, going over a ramp and through an arch, carrying an item, releasing an item and communicating messages. A complete list of the tasks and their descriptions are provided in the course handbook (Ghannam, 2019). These tasks were distributed in different locations within the University of Electronic Science and Technology in China (UESTC) campus. For example, a schematic diagram showing the three tasks to be completed in one

\footnotetext{
${ }^{2}$ According to the aforementioned references, MCQs are an effective summative assessment technique for testing guided or surface learning materials. The 3 main advantages of MCQs are:

1) MCQs have the potential to cover the whole of the syllabus.

2) They are especially suitable for "knowledge-based" subjects that are well defined, do not change rapidly with time and have unambiguous answers.

3) MCQs provide an easier method to analyse student performance.
} 
of UESTC's outdoor patios is shown in figure 3 and images of the tasks distributed around the UESTC campus are shown in figure 4 . A summary of the main tasks are as follows:

Task 1 - This involved instructing the rover to follow the meandering coloured path shown in the figure 4a. The rover should start somewhere near the arrow indicated in figure $4 \mathrm{~b}$ and should stop somewhere within the blue line indicated in figure 4a. The rover should therefore detect edges, colours and lines.

Task 2 - This involved finding the bridge and crossing it. The location of the bridge is shown in figure 4c. As shown in figure 4d, the bridge consisted of wire mesh and was approximately 0.45 of a metre in width and 2.2 metres in length - which included the dimensions of the ramps that would be used for the rover to roll up and off the bridge.

Task 3 - Once the rover had crossed the bridge, it should find the arch, go through it and stop.

Task 4 - In this task, the rover should demonstrate that it could carry and release fish food into the lake. The fish food should be released through the patio's railings, shown in figure 5 .

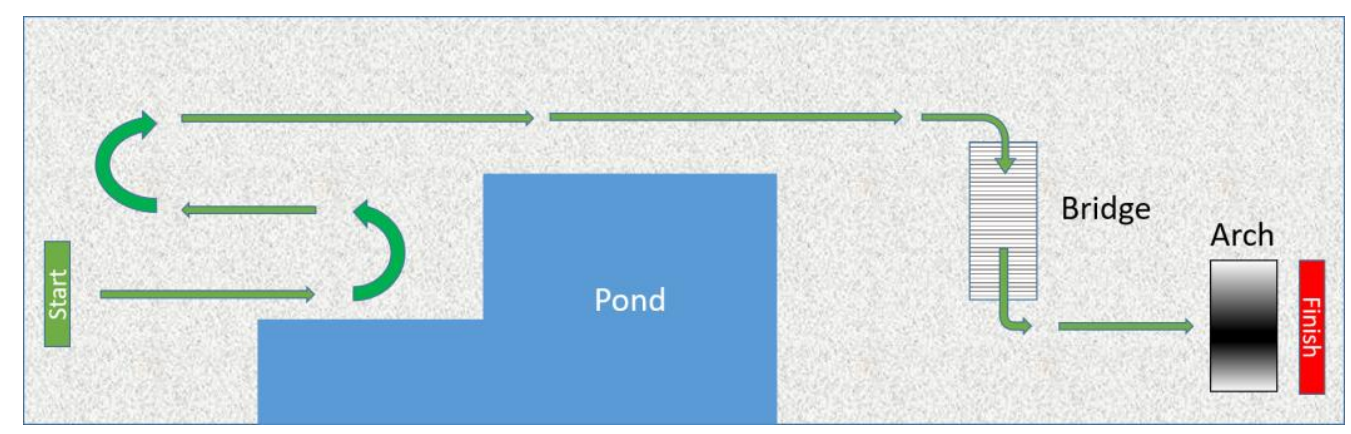

Figure 3: Schematic diagram of the robot's path.

Task 5 - Finally, the rover should stop and transmit a message to a laptop. The transmitted message should be a radio signal at $433 \mathrm{MHz}$. Moreover, the message must include the team number, team member names and the time of day (24-hour clock).

The main rules of the competition are summarised as follows:

1. The maximum cost of the project is $1000 \mathrm{RMB}$.

2. Each team will have a maximum of fifteen minutes to complete all the tasks.

3. A team that fails to begin within the first five minutes will be given a score of zero marks.

4. Rovers must run using a program previously downloaded to a microcontroller. Instructions cannot be transmitted in real time to the rover.

5. A total of two beacons can be used by the rover to assist it with navigation. Teams can propose any beacon design. The cost of the beacons should be included in the budget and bill of materials. Beacons should be carefully positioned before the start of the competition and cannot be moved afterwards.

6. Each task will be scored out of ten marks. Marks will be deducted for each external interference with the rovers.

7. Each team is expected to design a motor driver circuit and the PCB on which this circuit is constructed. 
The competition's objective was for students to complete the tracks with the least amount of interference from their teams. The rovers had to travel unaided around corners, along straight lines, over a bridge and through an arch. Furthermore, rovers had to be able to recognise colours, release an item and communicate three messages back to their teams. Teams with the least numbers of errors and interferences would score the highest marks and win the competition.

\subsection{Evaluation}

Finally, the evaluation phase involved gaining student feedback. Following the successful completion of this course, students were asked to take part in a survey. A questionnaire was divided into a number of sections, which aimed to probe student feedback regarding their teamwork learning experience. To appreciate the cultural differences and backgrounds of our students, we compared our findings with a similar TBL survey completed by 106 students from a UK university (Bentley and Warwick, 2013). 


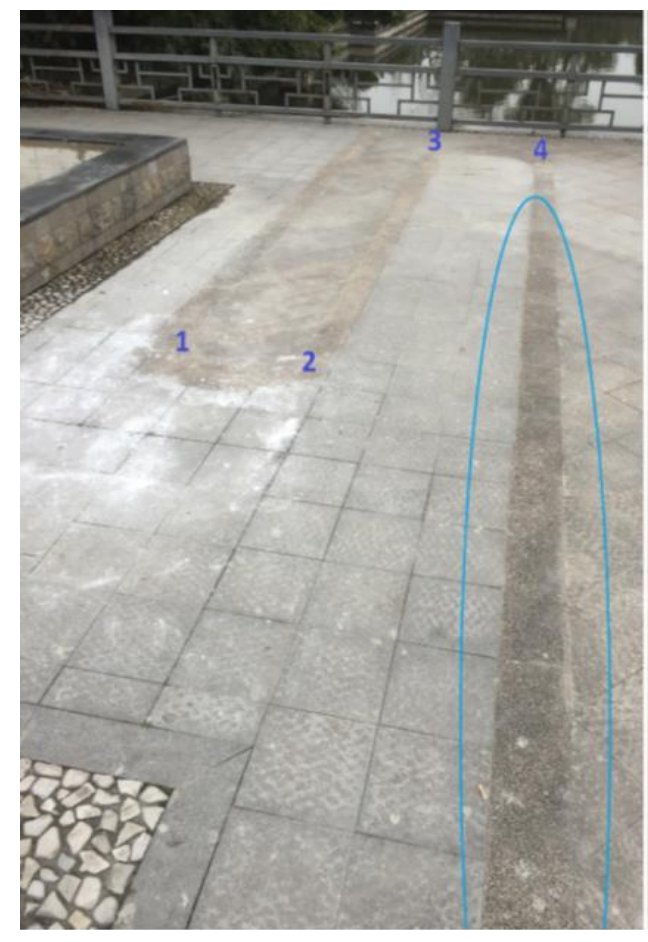

(a)

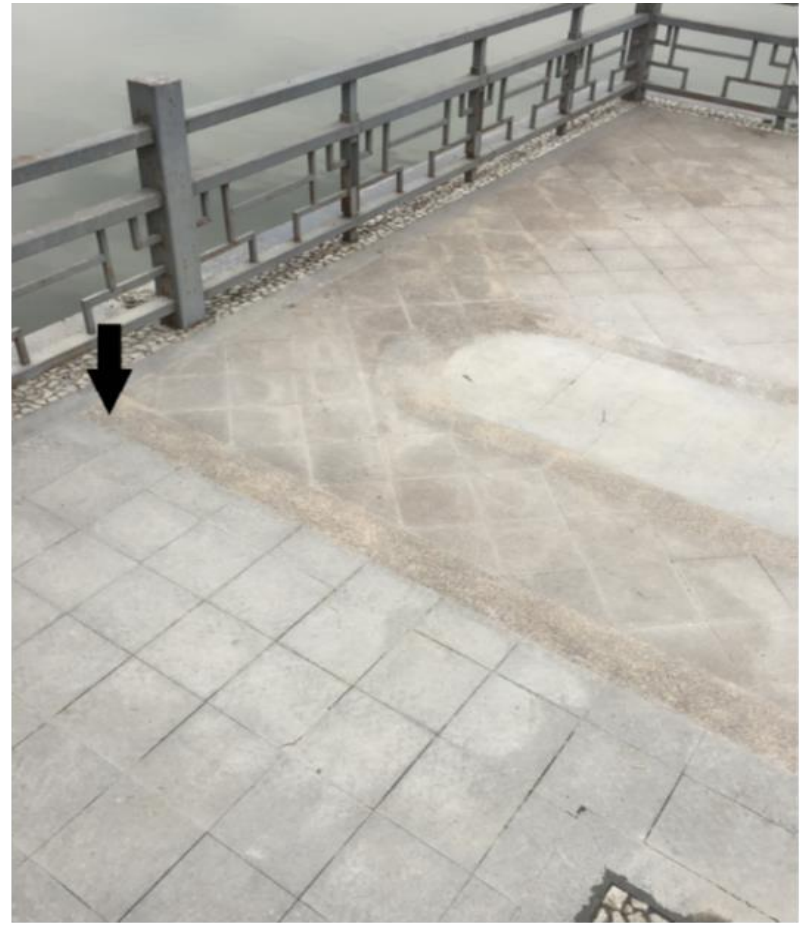

(b)

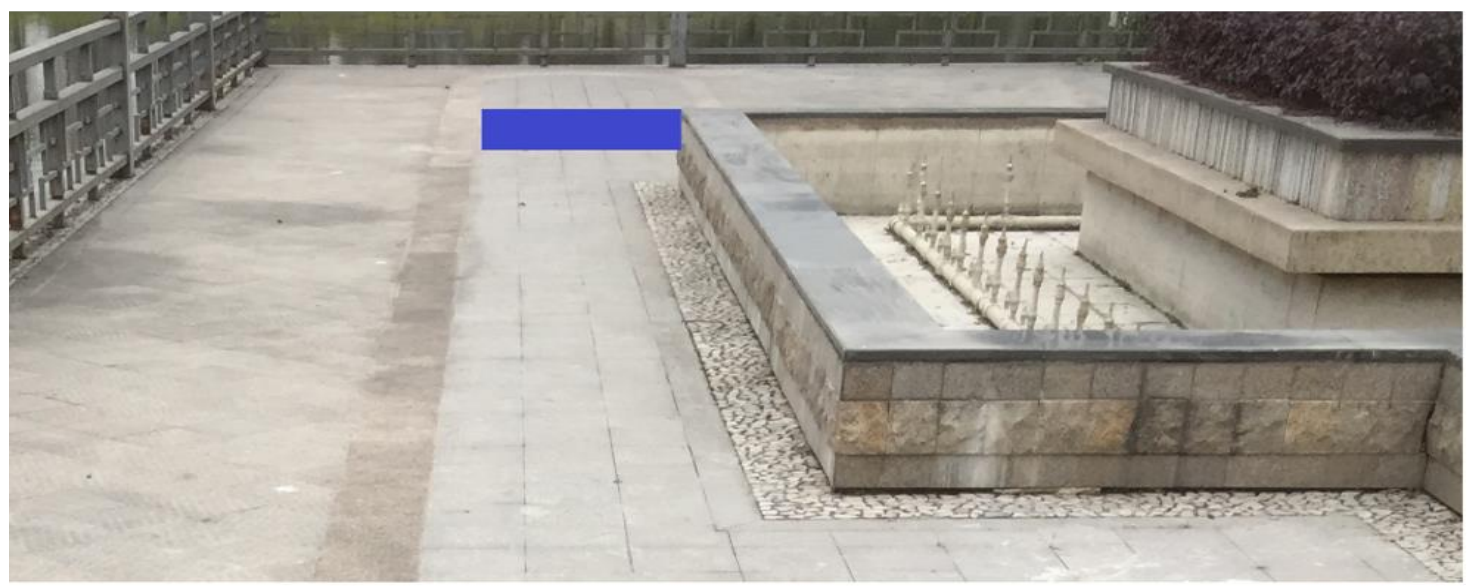

(c)

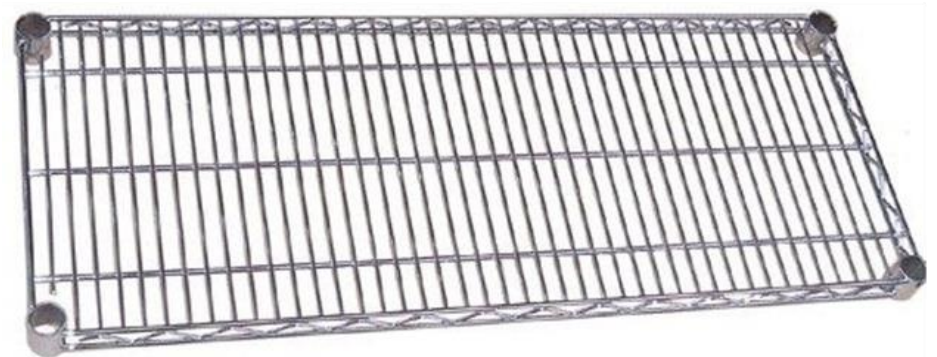

(d)

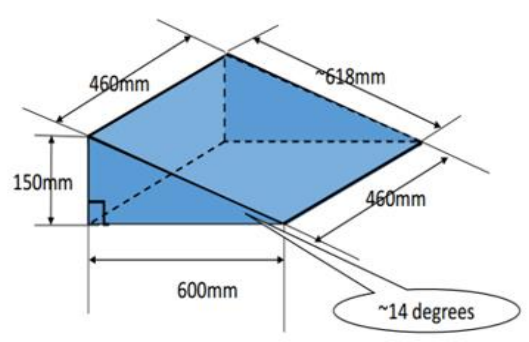

Figure 4: Image of the path that the rovers had to travel. To score full marks, the rovers had to turn at points 1, 2, 3 and 4 shown. They should then stop somewhere within the blue region. The rovers' starting position is shown in (b). The location of the bridge is shown in (c). The dimensions of the ramp and the texture of the bridge are shown in (d). 

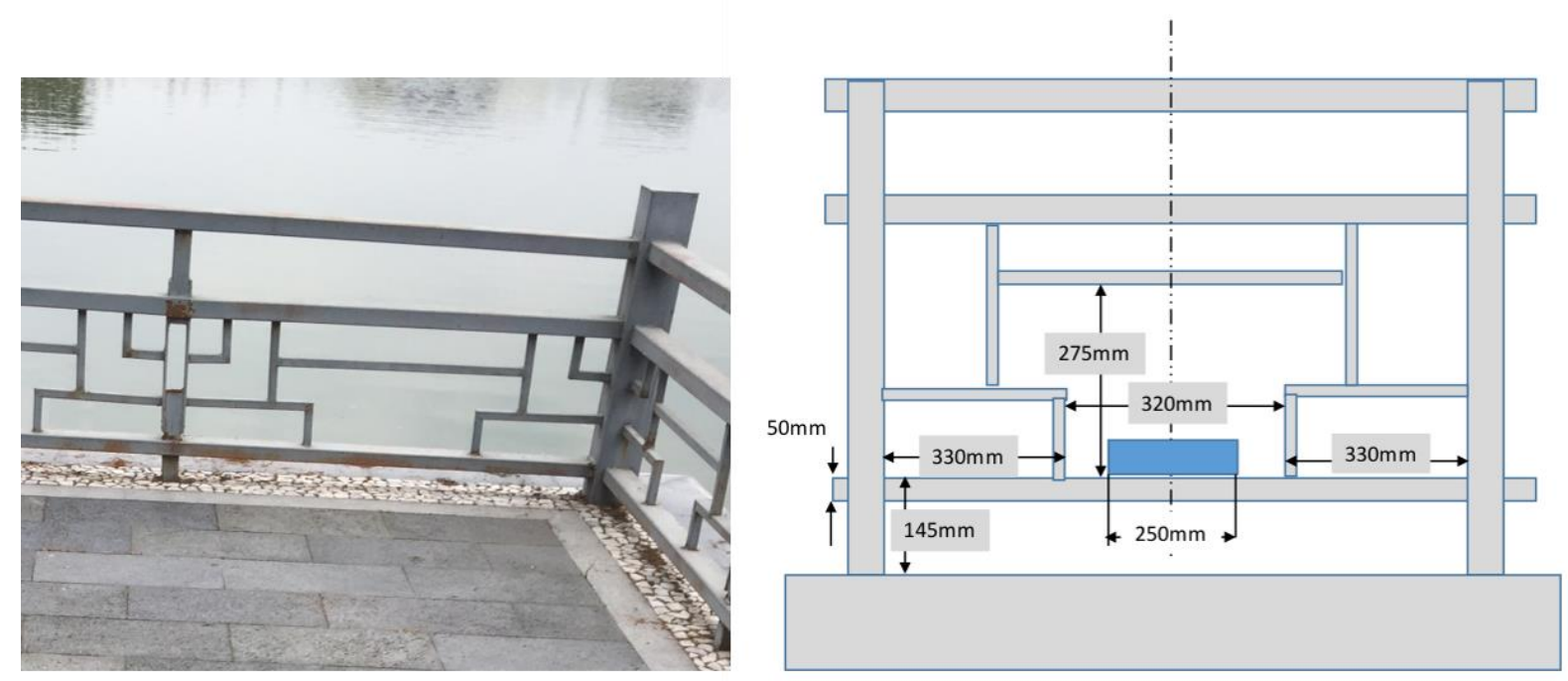

Figure 5: Schematic diagram of the patio railings that rovers needed to reach in order to release the fish food into the lake.

\section{Results and Discussions}

Sample images of the student rovers are shown in figure 6 . Results of the student questionnaires are shown in figures 7, 8 and 9.
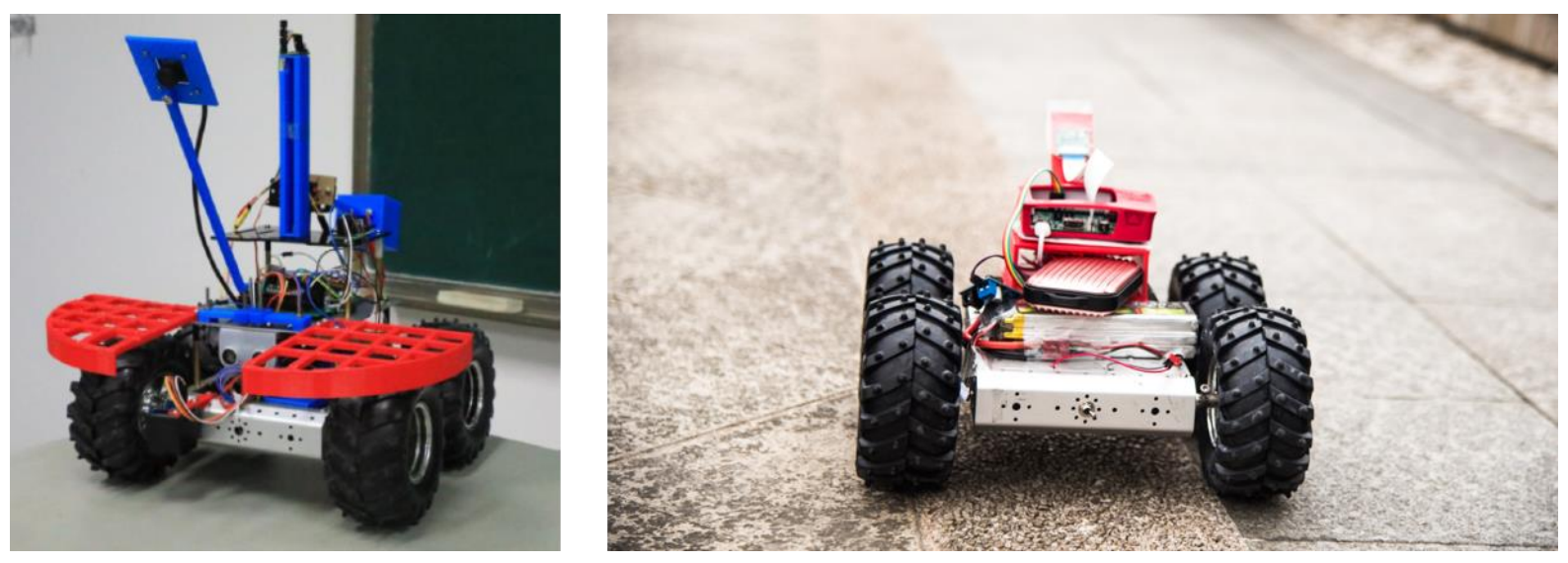

Figure 6: Sample images of the rovers that were developed by the students.

First, when asked whether students preferred team projects in comparison to individual group assignment, eighty-two per cent of students preferred team projects, as shown in figure $7 \mathrm{a}$ below. This was very different from the responses in the UK, where there was an almost even split in the preference of group and individual project work. This result may not seem surprising, considering that Chinese cultural values and philosophies are deeply rooted in Confucianism. These values are the basis of Chinese collectivism and solidarity (Hofstede et al., 2005; Wang et al., 2012), in contrast to Western individualism (Earley, 1993). 
- Individual $\square$ Team

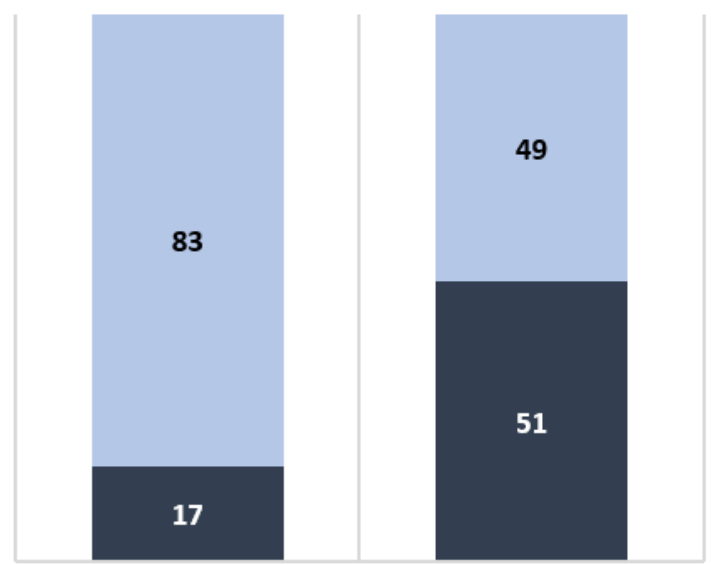

CHINA \%

(a)

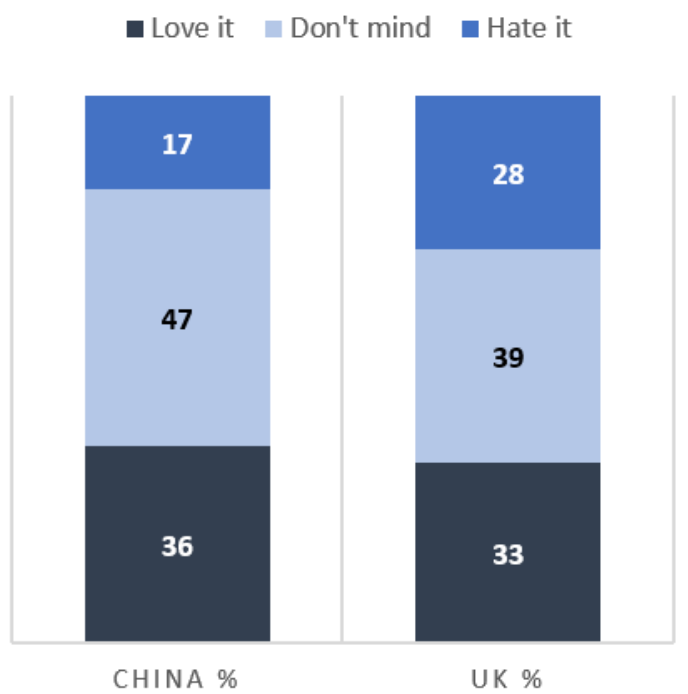

(c)
- Splitting up the work $\square$ Working together

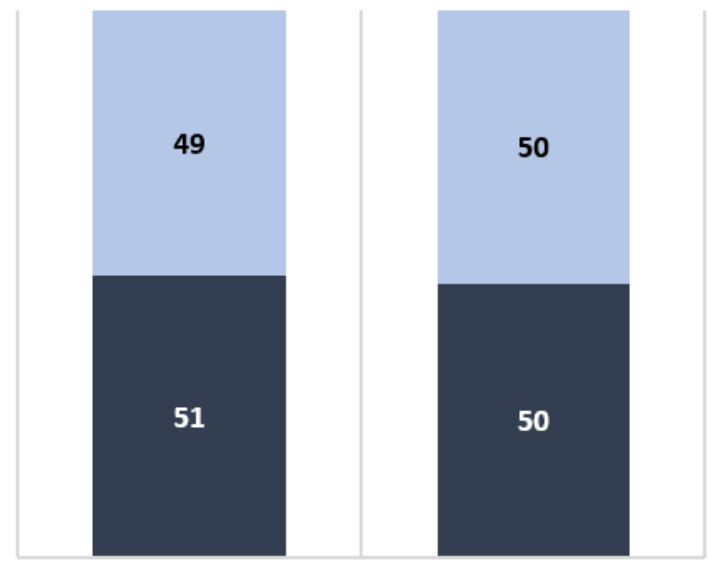

CHINA \%

(b)

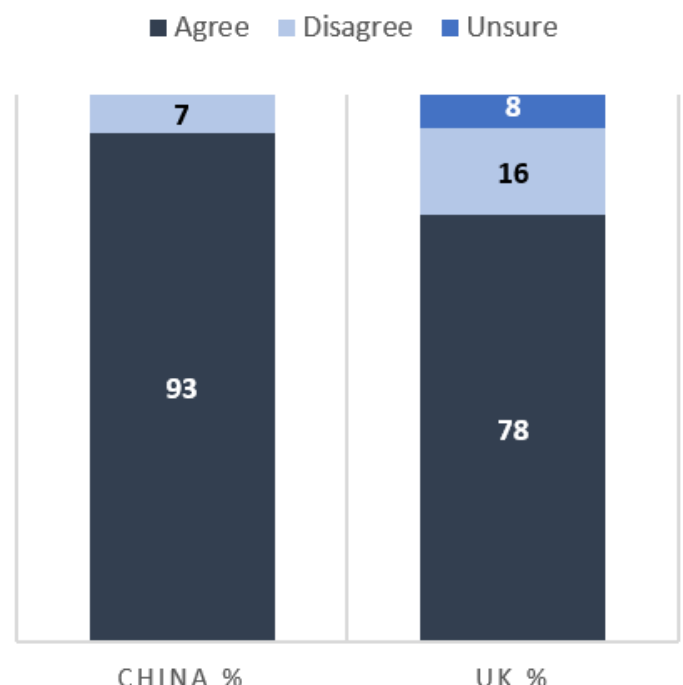

(d)

Figure 7: Comparison of UK and Chinese student responses when asked the following questions: (a) 'What do you prefer, individual or team projects?'; (b) 'What do you prefer when working on a team project?'; (c) 'How do you feel about assignments that require you to work together, but submit individual work?'; (d) 'Do you feel that you can learn more by working in a team?'

In terms of workload strategy, there was, as shown in figure $7 \mathrm{~b}$, an almost even preference towards either 'splitting the work' or 'working together' for both Chinese and British students. Moreover, when asked about how they felt towards group assignments requiring groups or teams to submit individual work, there was again almost similar agreement between Chinese and British students. On a scale of 0 to $5,36 \%$ of Chinese students mentioned that they 'loved it', which is very close to the same response of $33 \%$ of British students who were surveyed, as shown in figure 7c. A slightly larger percentage of British students strongly disliked the idea of working on a group project $(28 \%)$ that required the submission of an individual assignment, in comparison to only $17 \%$ of Chinese students. Consequently, in the case of our TDPS course, we asked students to submit both a group report and an individual 
reflection report at the end of the course. Furthermore, $93 \%$ of Chinese students were convinced that they were able to learn more by working in a team, fairly close in agreement with British students (78\%), as shown in figure $7 \mathrm{~d}$.

Regarding contributing more work than their fair share, there were again some contrasting responses between British and Chinese students, as shown in figure 8 . The majority of British and Chinese students 'would do it to improve the work and the grade' (27\% of Chinese $30 \%$ of British students). Surprisingly, few Chinese students (only $6 \%$ ) felt inclined to contribute more in order to help other group members. This was very different from British students, where $20 \%$ were prepared to do more work in order to help their team members. On the other hand, Chinese students felt obliged to contribute more work, if that was necessary (41\%), in comparison to only $10 \%$ of British students. Again, this is in perfect agreement with the nature of Chinese cultural values, which emphasises social affinity over personal interest (Chen and Lee, 2008).

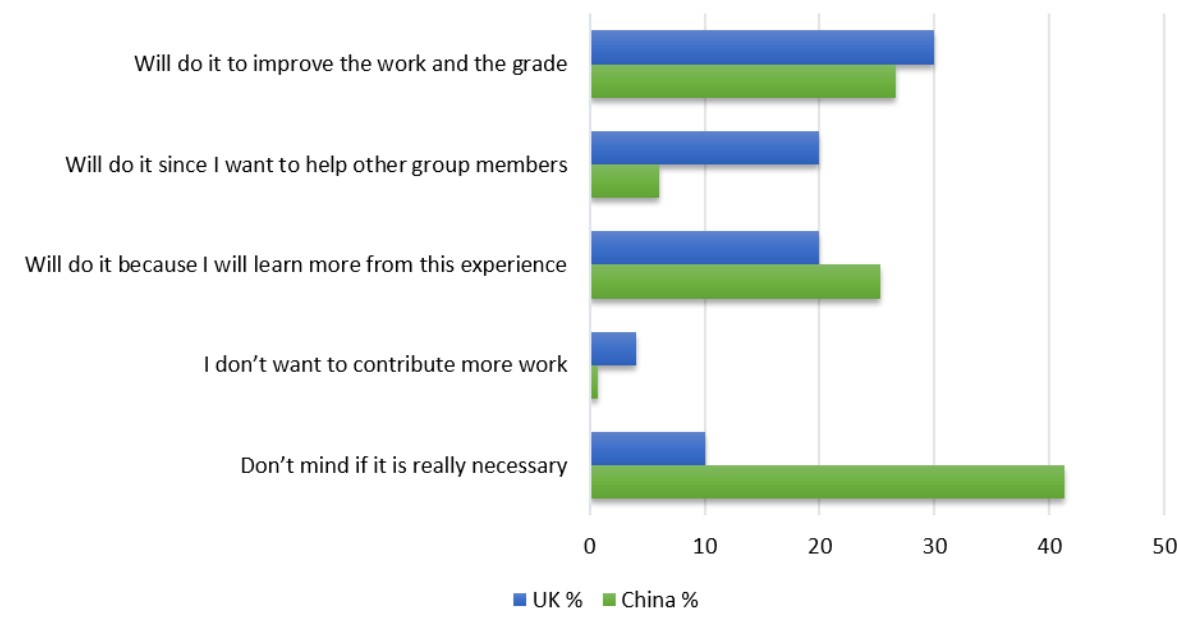

Figure 8: Comparison of UK and Chinese students when asked how they felt towards contributing more than their share.

Moreover, when Chinese students were asked about the tools that were used for communications purposes, almost $93 \%$ of students used social media tools, in comparison to almost $66 \%$ in the UK. Only $4 \%$ of Chinese students used tools that were provided by the university, such as Blackboard, Moodle and the University's email system.

As for the strategies that would be used to ensure a fair contribution from the group members, students were allowed to select multiple answers. These results are shown in figure 9. Both British and Chinese students favoured sharing ideas and information (47\% in comparison to $13 \%$ UK students) as well as setting deadlines (27.8\%) and sharing the workload (25.2\% of Chinese students, in comparison to $39 \%$ UK students). In comparison, UK students felt that only by setting deadlines could they split the work $(7 \%)$. 


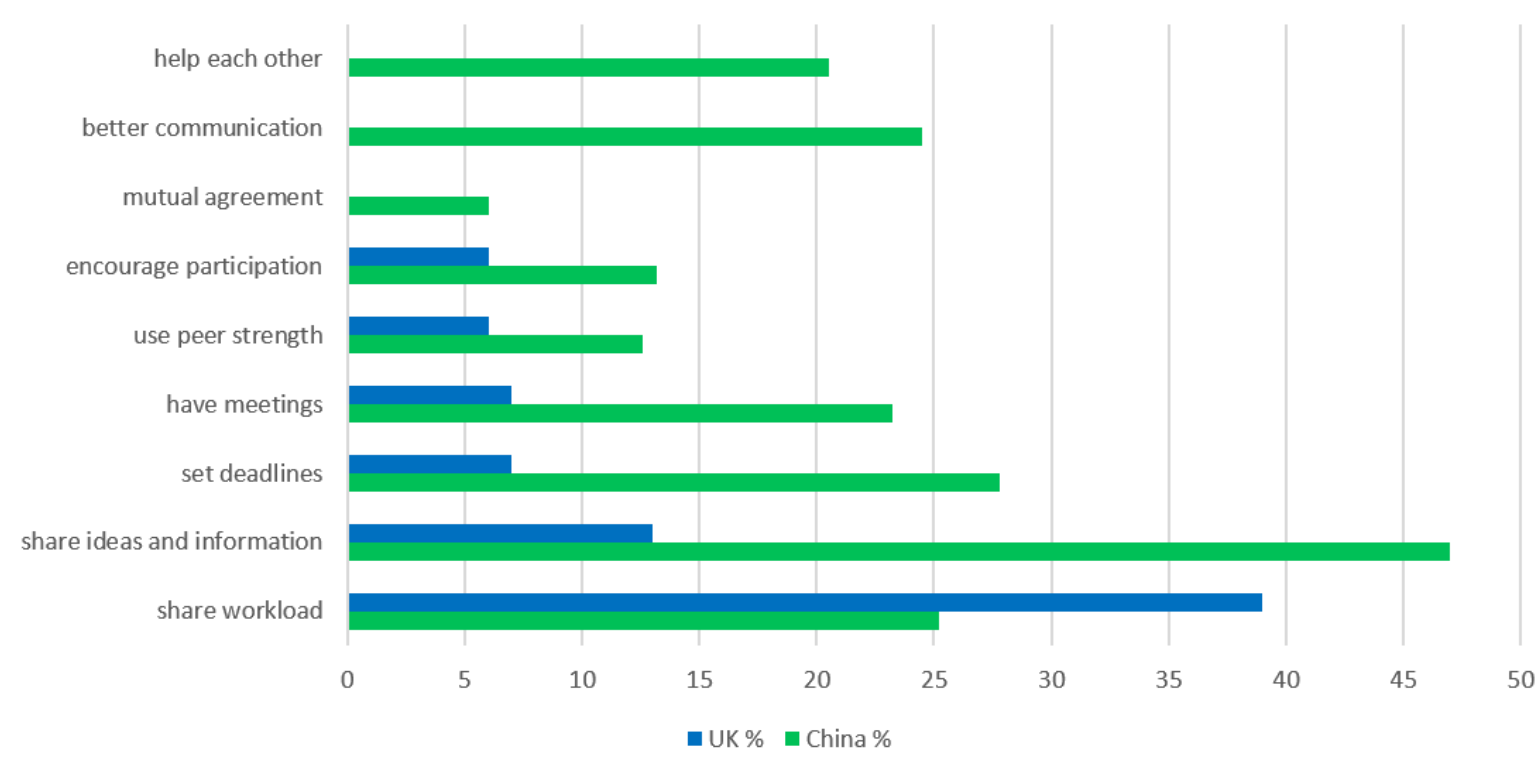

Figure 9: Comparison of UK and Chinese students when asked about their approach to assigning group work.

Interestingly, when asked about the biggest benefits of working in a team, the Chinese cohort of students provided a mixture of answers, such as: 'we can overcome obstacles together', 'increased creativity', 'ability to work more efficiently', 'solidarity', 'increased motivation', 'higher energy', 'less pressure on each individual', 'can easily approach team members when a problem arises', 'ability to make new connections' and 'joy of sharing success with others', in addition to more conventional answers such as 'more learning', 'sharing ideas' and 'sharing workload'. Similarly, UK respondent answers can be summarised as follows: 'Share information', 'share ideas', 'less workload', 'more input and ideas', 'more resources', 'help each other', 'more adaptable', 'more confident', 'can communicate with people of different culture', 'can exchange ideas', 'opportunity to understand and learn from others', 'become more knowledgeable' and 'build up relationship and make new friends'.

Finally, students were asked about the biggest drawbacks of working in a team. In some cases, British and Chinese students had similar responses, such as 'uneven contribution from team members', 'members rely on others' and 'poor time management'. Our Chinese students also provided variety of responses that included: 'conflicts between members', 'difficulties in finding a good leader', 'narrow specialisation in a certain area', 'difficulties in arranging meetings' and 'wasting too much time listening to the views of everyone'.

\section{Conclusions}

The literature claims that the use and implementation of active learning techniques can improve student interest in engineering degrees. We believe that this is particularly important in Western countries, where there has been a sustained decline in STEM applicants. Meanwhile, China produces over eight million STEM graduates each year, the majority of whom lack the necessary team-working skills required by the global job market. Consequently, we designed a new course for a transnational education programme that 
aimed to develop these skills. At the end of the course, students took part in a competition, which was well received by UESTC's senior management.

Our new third-year course was designed to encourage team-working skills. We strongly recommend that our approach to curriculum development is implemented in other programmes to improve student performance and to attract more students into pursuing an engineering degree. We also believe that TBL is particularly beneficial for teaching large cohorts, since it enables multiple teams to be facilitated by a single instructor, rather than multiple instructors.

According to feedback received from our students, ninety-three per cent were convinced that they were able to learn more by working in a team than by individual study. Consequently, students were able to transform their teams into more effective learning environments. Moreover, eighty-three per cent preferred team-based projects to individual ones. Our findings therefore prove that TBL is particularly suited to the culture and background of our transnational Chinese students. We therefore recommend the implementation of TBL in more engineering degrees. By the end of the course, students designed and developed rovers using their discipline-specific engineering skills as well as their team-working skills. As a result, students were able to learn from each other and run their own projects without undue reliance on the instructor.

\section{Reference list}

Ahmad, W., Ghannam, R. and Imran, M. (2019) Course design for achieving the graduate attributes of the 21st Century UK Engineer. In: Advance HE STEM Teaching and Learning Conference 2019, 30-31 January 2019, Birmingham, UK. Available at: https://www.advancehe.ac.uk/sites/default/files/2019-12/Session\%20abstracts.pdf (Accessed: 7 May 2020).

Bacon, D.R., Stewart, K.A. and Silver, W.S. (1999) 'Lessons from the best and worst student team experiences: How a teacher can make the difference.' Journal of Management Education, 23, 467-488. Available at: https://journals.sagepub.com/doi/abs/10.1177/105256299902300503?journalCode=imed (Accessed: 7 May 2020).

Baig, M., Ali, S.K., Ali, S. and Huda, N. (2014) 'Evaluation of multiple choice and short essay question items in basic medical sciences.' Pakistan Journal of Medical Sciences, 30, 3-6. Available at: http://pjms.com.pk/index.php/pjms/article/view/4458/2112 (Accessed: 7 May 2020).

Bentley, Y. and Warwick, S. (2013) 'Students' experience and perceptions of group assignments.' Journal of Pedagogic Development, 3, 11-19. Available at: https://s3.eu-west2.amazonaws.com/assets.creode.advancehe-documentmanager/documents/hea/private/gen 1760 1568037085.pdf (Accessed: 7 May 2020). 
British Council. (2018) Employability in Focus: Exploring Employer Perceptions of Overseas Graduates Returning to China. British Council International Education Services Report.

Available at:

https://www.agcas.org.uk/write/MediaUploads/Resources/ITG/British Council Employability in Focus China.pdf (Accessed: 7 May 2020).

Carberry, A.R. and Baker, D.R. (2018) 'The impact of culture on engineering and engineering education.' In: Dori Y., Mevarech Z., Baker D. (eds) Cognition, metacognition, and culture in STEM education. 217-239. New York: Springer. ISBN 978-3-319-66659-4.

Available at: https://link.springer.com/chapter/10.1007/978-3-319-66659-4 10 (Accessed: 7 May 2020).

Chan, J., Goh, J. and Prest, K. (2015) Soft skills, hard challenges: Understanding the nature of China's skills gap. British Council. Available at:

https://www.britishcouncil.org/sites/default/files/china skills gap report final web.pdf (Accessed: 7 May 2020).

Chen, C-C. and Lee, Y-T. (2008) Leadership and management in China: Philosophies, theories, and practices. Cambridge: Cambridge University Press. ISBN 978-0-511-75376-3. Available at: https://www.cambridge.org/core/books/leadership-and-management-inchina/F5E77B85C5A9152F1C626F1E491B9402 (Accessed: 7 May 2020).

Dunne, E. and Rawlins, M. (2000) 'Bridging the gap between industry and higher education: Training academics to promote student teamwork.' Innovations in Education and Training international, 37, 361-371. Available at:

https://www.tandfonline.com/doi/abs/10.1080/135580000750052973 (Accessed: 7 May 2020).

Earley, P.C. (1993) ‘East meets West meets Mideast: Further explorations of collectivistic and individualistic work groups.' Academy of Management Journal, 36, 319-348. Available at: https://www.jstor.org/stable/256525?seq=1 (Accessed: 8 May 2020).

Ejiwale, J. (2013) 'Barriers to successful implementation of STEM education.' Journal of Education and Learning, 7, 63-74. Available at:

https://www.neliti.com/publications/71913/barriers-to-successful-implementation-of-stemeducation (Accessed: 8 May 2020).

Eningeering Council UK. (2014) Accreditation of Higher Education Programmes: UK Standard for Professional Engineering Competence. London: Engineering Council UK. Available at:

https://www.engc.org.uk/EngCDocuments/Internet/Website/Accreditation\%20of\%20Higher\% 20Education\%20Programmes\%20third\%20edition\%20(1).pdf (Accessed: 13 November 2019).

Finelli, C.J., Daly, S.R. and Richardson, K.M. (2014) 'Bridging the research-to-practice gap: Designing an institutional change plan using local evidence.' Journal of Engineering Education, 103, 331-361. Available at: https://onlinelibrary.wiley.com/doi/10.1002/jee.20042 (Accessed: 8 May 2020). 
Freeman, M. (2012) 'To adopt or not to adopt innovation: A case study of team-based learning.' The International Journal of Management Education, 10, 155-168. Available at: https://www.sciencedirect.com/science/article/abs/pii/S1472811712000353 (Accessed: 8 May 2020).

Freeman, S., Eddy, S., Mcdonough, M., Smith, M., Okoroafor, N., Jordt, H. and Wenderoth, M. (2014) 'Active learning increases student performance in science, engineering, and mathematics.' Proceedings of the National Academy of Sciences, 111, 8410-8415. Available at: https://www.pnas.org/content/111/23/8410 (Accessed: 8 May 2020).

Fry, H., Ketteridge, S. and Marshall, S. (2008) A handbook for teaching and learning in higher education: Enhancing academic practice, New York: Routledge. ISBN 0-203-89141-4. Available at:

https://books.google.co.uk/books?hl=en\&lr=\&id=5Rp9AgAAQBAJ\&oi=fnd\&pg=PP1\&ots= dn Fhcn6Vq\&sig=Zwk-ATuxFnocqL Oigzj|HpNjKs\#v=onepage\&q\&f=false (Accessed: 8 May 2020).

Gallegos, P. and Peeters, M. (2011) 'A measure of teamwork perceptions for team-based learning.' Currents in Pharmacy Teaching and Learning, 3, 30-35. Available at: https://www.sciencedirect.com/science/article/pii/S1877129710000985?casa token=nsIWrFr oSZMAAAAA:D1VZ3V963GfyONYCDAgNUulnIHX OR23tU1haXWwQ de5qQwOVLoCB4DUk-PAFWrcLzODWZcg (Accessed: 8 May 2020).

Ghannam, R. (2019) Team Design and Project Skills Course Handbook. Glasgow: The University of Glasgow. Available at: https://edshare.gla.ac.uk/395/ (Accessed: 13 November 2019).

Great Britain Department for Business Energy and Industrial Strategy (2017) Industrial Strategy: building a Britain fit for the future. London: HM Government. Available at: https://assets.publishing.service.gov.uk/government/uploads/system/uploads/attachment da ta/file/664563/industrial-strategy-white-paper-web-ready-version.pdf (Accessed: 8 May 2020).

Haidet, P. and Fecile, M. (2006) 'Team-based learning: a promising strategy to foster active learning in cancer education.' Journal of Cancer Education, 21, 125-128. Available at: https://www.tandfonline.com/doi/abs/10.1207/s15430154jce2103 6 (Accessed: 8 May 2020).

Hake, R.R. (1998) 'Interactive-engagement versus traditional methods: A six-thousandstudent survey of mechanics test data for introductory physics courses.' American Journal of Physics, 66, 64-74. Available at: https://aapt.scitation.org/doi/10.1119/1.18809 (Accessed: 8 May 2020).

Han, X. and Appelbaum, R.P. (2018) 'China's science, technology, engineering, and mathematics (STEM) research environment: A snapshot.' PloS one, 13, e0195347. Available at: https://journals.plos.org/plosone/article?id=10.1371/journal.pone.0195347 (Accessed: 8 May 2020). 
Hofstede, G., Hofstede, G.J. and Minkov, M. (2010) Cultures and organizations: Software of the mind. New York: McGraw-Hill. ISBN 978-0-07-177015-6. Available at: https://eedu.nbu.bg/pluginfile.php/900222/mod resource/content/1/G.Hofstede G.J.Hofstede M.Min kov\%20-\%20Cultures\%20and\%20Organizations\%20-

\%20S oftware\%20of\%20the\%20Mind\%203rd edition\%202010.pdf (Accessed: 8 May 2020).

Jamieson, L. and Lohmann, J. (2012) Innovation with Impact: Creating a Culture for Scholarly and Systematic Innovation in Engineering Education. Washington: American Society for Engineering Education. ISBN 978-0-878-23240-0. Available at:

https://www.asee.org/member-resources/reports/Innovation-with-Impact (Accessed: 8 May 2020).

Michaelsen, L.K. and Sweet, M. (2008) 'The essential elements of team-based learning.' New Directions for Teaching and Learning, 2008, 7-27. Available at:

https://onlinelibrary.wiley.com/doi/abs/10.1002/tl.330 (Accessed: 8 May 2020).

Miller, R. and Euchner, J. (2014) 'The Future of Engineering Education: An Interview with Rick Miller.' Research-Technology Management, 57, 15-19. Available at:

https://www.tandfonline.com/doi/abs/10.5437/08956308X5701003 (Accessed: 8 May 2020).

Moeen-Uz-Zafar Khan, B.M. (2011) 'Evaluation of modified essay questions (MEQ) and multiple choice questions (MCQ) as a tool for assessing the cognitive skills of undergraduate medical students.' International Journal of Health Sciences, 5, 39-43. Available at: https://www.ncbi.nlm.nih.gov/pmc/articles/PMC3312767/pdf/ijhs5 1p039.pdf (Accessed: 8 May 2020).

Murzi, H.G. (2014) 'Team-based learning theory applied to engineering education: A systematic review of literature.' In: 121st American Society for Engineering Education Annual Conference \& Exposition, 15-18 June 2014, Indianapolis, USA. Available at:

https://www.asee.org/public/conferences/32/papers/10751/view (Accessed: 8 May 2020).

Olson, S. and Riordan, D.G. (2012) Engage to Excel: Producing One Million Additional College Graduates with Degrees in Science, Technology, Engineering, and Mathematics. Report to the President. Executive Office of the President. Available at: https://files.eric.ed.gov/fulltext/ED541511.pdf (Accessed: 8 May 2020).

O'Dwyer, A. (2007) Experiences of assessment using multiple-choice questions on a first year module in electrical engineering. In: Brabazon, D. and Olabi, A.G. (eds.) ISEE-07: Proceedings of the International Symposium for Engineering Education, ISEE-07, 17-19 September 2007, Dublin City University, Dublin, Ireland. 189-193. Available at: http://doras.dcu.ie/447/1/Odwyer-Assessment ISEE07.pdf (Accessed: 8 May 2020).

Parmelee, D. and Michaelsen, L. (2010) 'Twelve tips for doing effective Team-Based Learning (TBL).' Medical Teacher, 32, 118-122. Available at: https://www.tandfonline.com/doi/abs/10.3109/01421590903548562?journalCode=imte20 (Accessed: 8 May 2020). 
Parmelee, D., Michaelsen, L.K., Cook, S. and Hudes, P.D. (2012) 'Team-based learning: a practical guide: AMEE guide no. 65.' Medical Teacher, 34, e275-e287. Available at: https://www.tandfonline.com/doi/full/10.3109/0142159X.2012.651179 (Accessed: 8 May 2020).

Price, A., Rimington, R., Chew, M-T. and Demidenko, S. (2010) 'Project-based learning in robotics and electronics in undergraduate engineering program setting.' In: 2010 Fifth IEEE International Symposium on Electronic Design, Test \& Applications, 13-15 January 2010, Ho Chi Minh City, Vietnam. 188-193. Available at: https://ieeexplore.ieee.org/document/5438692 (Accessed: 8 May 2020).

Stapleton, K. (2017) 'China now produces twice as many graduates a year as the US.' World Economic Forum. Available at: https://www.weforum.org/agenda/2017/04/higher-educationin-china-has-boomed-in-the-last-decade (Accessed: 8 May 2020).

Thomas, P.A. and Bowen, C.W. (2011) 'A controlled trial of team-based learning in an ambulatory medicine clerkship for medical students.' Teaching and Learning in Medicine, 23, 31-36. Available at: https://www.tandfonline.com/doi/abs/10.1080/10401334.2011.536888 (Accessed: 8 May 2020).

Vasan, N.S., Defouw, D.O. and Compton, S. (2011) 'Team-based learning in anatomy: An efficient, effective, and economical strategy.' Anatomical Sciences Education, 4, 333-339. Available at: https://anatomypubs.onlinelibrary.wiley.com/doi/abs/10.1002/ase.257 (Accessed: 8 May 2020).

Vogt, C.M. (2008) 'Faculty as a critical juncture in student retention and performance in engineering programs.' Journal of Engineering Education, 97, 27-36. Available at: https://onlinelibrary.wiley.com/doi/abs/10.1002/j.2168-9830.2008.tb00951.x (Accessed: 8 May 2020).

Wang, C.L., Tee, D.D. and Ahmed, P.K. (2012) 'Entrepreneurial leadership and context in Chinese firms: a tale of two Chinese private enterprises.' Asia Pacific Business Review, 18, 505-530. Available at: https://www.tandfonline.com/doi/abs/10.1080/13602381.2012.690257 (Accessed: 8 May 2020).

Williams, J.B. (2006) 'Assertion-reason multiple-choice testing as a tool for deep learning: a qualitative analysis.' Assessment \& Evaluation in Higher Education, 31, 287-301. Available at: https://www.tandfonline.com/doi/abs/10.1080/02602930500352857 (Accessed: 8 May 2020).

Zgheib, N.K., Simaan, J.A. and Sabra, R. (2010) 'Using team-based learning to teach pharmacology to second year medical students improves student performance.' Medical Teacher, 32, 130-135. Available at:

https://www.tandfonline.com/doi/abs/10.3109/01421590903548521?journalCode=imte20 (Accessed: 8 May 2020).

Zhang, D., Yao, N., Cuthbert, L. and Ketteridge, S. (2014) A suggested strategy for teamwork teaching in undergraduate engineering programmes particularly in China. In: 2014 IEEE Frontiers in Education Conference, 22-25 October 2014, Madrid, Spain. 1-8. Available at: https://ieeexplore.ieee.org/document/7044077 (Accessed: 8 May 2020). 